Educational Research for Social Change (ERSC)

Volume 10 No. 2 September 2021

pp. 124-141

ersc.nmmu.ac.za

ISSN: 2221-4070

\title{
Narrative Imagination and Social Change: Instructors in Agricultural Colleges in Ethiopia Address Sexual and Gender-Based Violence ${ }^{1}$
}

\author{
S. M. Hani Sadati \\ ORCID No: 0000-0002-2729-7989 \\ McGill University \\ hani.sadati@mail.mcgill.ca
}

Claudia Mitchell iD

ORCID No: 0000-0002-9790-2486

McGill University

claudia.mitchell@mcgill.ca

\begin{abstract}
Ethiopia has one of the highest rates of sexual and gender-based violence (SGBV) in the world, making female students particularly vulnerable in its post-secondary institutions. Although there is extensive literature that describes the problem, mainly from the students' perspectives, what remains understudied is the role of instructors, their perception of the current issues, and what they imagine they can do to address campus-based SGBV, particularly in rural settings. In this study, we used the concept of narrative imagination to work with instructors in four Ethiopian agricultural colleges to explore how they understand the SGBV issues at their colleges and what they imagine their own role could include in efforts to combat these problems. Using qualitative narrative-based methods such as interviews and an interactive storyline development workshop, as well as cellphilming (cellphone + film) as a participatory visual method, the data were collected across several fieldwork phases. We consider how we might broaden this framework of narrative imagination to include the notion of art for social change.
\end{abstract}

Keywords: sexual and gender-based violence, post-secondary education, narrative imagination, professional learning, storytelling

Copyright: () 2021 Sadati and Mitchell

This is an open access article distributed under the terms of the Creative Commons Attribution NonCommercial License, which permits unrestricted non-commercial use, distribution, and reproduction in any medium, provided the original author and source are credited.

Please reference as: Sadati, S. M. H. and Mitchell, C. (2021). Narrative Imagination and Social Change: Instructors in Agricultural Colleges in Ethiopia Address Sexual and Gender-Based Violence Educational Research for Social Change, 10 (2), 124-141. http://dx.doi.org/10.17159/2221$\underline{4070 / 2021 / \mathrm{v} 10 \mathrm{i} 2 \mathrm{a} 8}$

${ }^{1}$ Ethical clearance: McGill University's Certificate of Ethical Acceptability of Research Involving Humans (File \#: 27-0618) 


\section{Introduction}

"Imagination gives us images of the possible that provide a platform for seeing the actual," according to the well-known arts in education theorist, Elliot Eisner, who went on to say that "by seeing the actual freshly, we can do something about creating what lies beyond it" $(2002$, p. 4). This is crucial to imagining solutions to urgent global concerns such as the high rates of sexual and gender-based violence (SGBV), an issue that affects one in three women in their lifetime, according to the World Bank (2019). This report draws attention to the individual and socioeconomic costs of SGBV for communities and to the fact that it needs to be addressed throughout the Global North and the Global South. As has been evident in much of the global research on SGBV in educational settings, learning institutions are often breeding grounds for power imbalances that result in high rates of SGBV (Leach \& Mitchell, 2006). The situation for young women in colleges and universities in sub-Saharan Africa (SSA) is particularly worrying. In their meta-analysis and systematic review of studies that targeted SGBV among young women in educational institutions (schools, universities, and colleges) in SSA, Beyene et al. (2019) reported a high prevalence of various types of gender-based violence with Ethiopia having one of the highest rates. A more recent systematic review and meta-analysis that considered two decades (2000 to 2020) of studies on the prevalence and related risk factors of SGBV in higher education settings in Ethiopia, showed that "the lifetime prevalence of sexual violence among female students in [such] institutions ... was high," ranging from $14.3 \%$ among female students at Hawassa University to $76.4 \%$ at Ambo University (Kefale et al., 2021, p. 3). A review of the literature from Ethiopia shows that various types of SGBV are problems faced by significant numbers of females in post-secondary education contexts in different regions (Adinew \& Hagos, 2017; Arnold et al., 2008; Gelaye et al., 2009; Kassa et al., 2019; Mamaru et al., 2015; Shimekaw et al., 2013; Takele \& Setegn, 2014; Tora, 2013).

To date, most of the studies conducted in post-secondary institutions in SSA are typically student surveys that attempt to document the magnitude of SGBV. In previous work with agricultural colleges in rural areas of Ethiopia, a survey of more than 1,500 students captured their perceptions of many different types of SGBV in four colleges (Mitchell \& Starr, 2018). In follow-up work with a group of instructors from these four colleges, these scholars engaged in a participatory data analysis exercise of the survey data and it was clear that the instructors were committed to finding strategies to address the situation, as Starr and Mitchell (2018) have noted. While documenting the extent of the issue is a crucial first step in combating SGBV, there is clearly a need for interventions that align with the growing recognition that learning institutions should not only be places where it is safe for everyone to learn, but should also be spaces of transformation-particularly in the context of gender equity and social justice. In these places, it should be possible to imagine more equitable futures. Taking into consideration the positive response of instructors, what might we learn from their engaging in a "narrative imagination" process that Brockmeier (2009) identified as "pivotal in probing and extending real and fictive scenarios of agency" (p. 215)? How might this work contribute within a broader art for social change framework? Building on the idea of storytelling from the perspective of narrative imagination and using participatory visual arts-based tools, we explore how instructors at four Ethiopian agricultural colleges imagine and visualise what their roles as instructors could be in addressing issues of campus-based SGBV.

\section{Imagination and Storying: A Framework for Studying Social Change}

The term change inherently contains the meaning of moving toward a goal, or target, or desired condition. Similar to the concept of intentionality in phenomenology, which identifies the experience of consciousness as being directed toward something (Smith, 2018), social change is also aimed in a specific direction. How do change agents visualise this direction toward altering symbols, rules, values, and organisations? Hawlina et al. (2020) have referred to imagination as a key element in social movements and in social change. Human beings are able to make social and political change because 
they "not only shape and imagine the world around them and their position in it, but also ... re-shape and re-imagine it" (Graef et al., 2020, p. 433). Jenkins et al. have called this process "civic imagination" and defined it "as the capacity to imagine alternatives to current cultural, social, political, or economic conditions"; the civic agents of change are capable of imagining the process of change because "one cannot change the world without imagining what a better world might look like" (2020, p. 5).

But, as Zittoun and Gillespie (2015) have asked, "How can we have access to imagining?" (p. 11), and how can we study it? In response, they offered a methodological strategy that explores externalised examples of imagination such as writings, self-reports or other artifacts, and multimodal texts. An externalised imagination could take the form of narrative and storytelling, both of which have already been considered as strategies toward achieving transformation and social change (Müller, 2019; Razack, 2006). Graef et al. (2020) considered storytelling's "co-constructed and dynamic nature" to be the driver of "social and political change" (p. 433). In this context, to be able to identify the required steps of transforming from "current reality" to "a hoped for but as yet unrealised reality," as Andrews (2014) has pointed out, "one must first create some sort of narrative emplotment, which includes characters, plot (or action), and a desired endpoint" (p. 5). Narrating the stories leads to better understanding and enables the agents of change to visualise their desired world and transfer their thoughts and meanings to others. Brockmeier (2009) considered storytelling to be an innovative means of communication, negotiation, and meaning-making and recommended "narrative imagination as a form and practice of human agency" (p. 227). From the perspective of narrative imagination, bridging the pathways between the current situation and the desired one or between the present and a potential future is key (Andrews, 2014). Sools (2020) provided a brief review of future-oriented approaches or what she termed "prospective methodologies" (p. 451), and noted that scholars with this viewpoint commonly highlight the connection between future and present and use this framework to understand "how imagining possible and preferred future guides and motivates present thought and action" (p. 451-452).

Closely linked to the idea of Sools's (2020) prospective methodologies, is the work on communitybased visual methodologies for social change using arts-based methods such as photovoice, participatory video/cellphilming (cellphone + film), and digital story-telling as the contributors to de Lange et al. (2007) have highlighted; see, too, Mitchell et al. (2017). Located within the broad area of art as an agent for social change (see the chapters in Mreiwed et al., 2020), typically, these methods engage participants in picturing change. Seen through the eyes of local participants, what are the issues and what are the solutions? And notwithstanding the critique of sometimes being overly celebratory (Low et al., 2012), such methods are, in a sense, utopic in relation to imagining a different future at a local level, such as imagining the creation of safer toilets in a primary school (Mitchell, 2009). Applied to studying the potential for the narrative imagination of instructors in agricultural colleges to contribute to addressing SGBV, we consider the words of well-known curriculum theorist, Maxine Greene. As she explained, "engagements with the arts [can] release the imaginative capacity into play [and foster] a commitment to the risky search for alternative possibilities" (Greene, 1999, p. 47-48).

\section{Methodology}

Our study is located within what Mertens (2008) referred to as a transformative paradigm. As researchers, we are committed to finding ways to work directly and through participatory approaches with communities to support the idea of research as intervention (D'Amico et al., 2016). 


\section{Participants}

The fieldwork was led by the first author and carried out with instructors from four agricultural colleges in four regions of Ethiopia: Maichew, Nedjo, Wolaita Sodo, and Woreta. Located within a large project, Agricultural Transformation Through Stronger Vocational Education (ATTSVE), which focuses on the transformation of agricultural colleges in Ethiopia, ${ }^{2}$ the fieldwork involved five instructors from each of the four colleges with at least one to two women from each college to make sure we have women's voices in each group. ${ }^{3}$ In total, 20 instructors with the age range of 23 to 60 years, and work experience of 3 to 31 years, participated in the data gathering processes. Aligning with the structure of ATTSVE, most of the participant instructors were attached to the gender clubs in their colleges as gender officers. Involving these instructors meant that they had already had some exposure to issues of gender and SGBV and also, that they were key actors in the transformation agenda of these colleges.

\section{Data Collection}

The fieldwork was part of a larger study that tested a participatory game design process for developing a serious game that could ultimately become a self-educating tool (Sadati, 2019) ${ }^{4}$ to support instructors in addressing SGBV on agricultural campuses (see Sadati \& Mitchell, 2021). Serious games can create entertaining experiences that are also educational (Abt, 1987). To create our educational game, we first needed to carry out research to explore the educational needs of the instructors and develop the game's learning objectives. Under the general participatory action research approach, the entire data gathering process included five techniques: individual interviews, group discussions, cellphilm production, participatory game storyline development, and feedback collection. In this article, we focus on the narratives of instructors across three of five data collection techniques.

\section{Individual Interviews}

Twenty instructors, five from each college, participated in individual semi-structured interviews during which they spoke about their knowledge, experience, and observations of SGBV on campus, and its causes and consequences. Interviews were carried out in instructors' colleges and in closed rooms where they felt comfortable to speak about their experiences. Each interview, on average, lasted about an hour. We took notes of the conversations and obtained instructors' consent to record the interviews for later review.

\section{Cellphilm (Cellphone + Film) Production}

This is a participatory visual research approach (see Tomaselli et al., 2010) that is used to involve research participants in a process of making short videos in response to a question or a prompt about a community issue. Within the framework of participatory visual methods (Mitchell et al., 2017), cellphilm production is a collective activity during which participants are co-producers of knowledge through sharing their understandings of, experiences with, and solutions to, a community issue. As Mitchell et al. (2016) have highlighted, typically, this is done through a workshop approach based on a

\footnotetext{
2 The ATTSVE project aimed to help improve Ethiopia's agricultural system by strengthening Agricultural Technical and Vocational Education Training (ATVET) colleges. As part of this six-year study, the second author led the component that focused on gender equality and inclusiveness in the colleges.

${ }^{3}$ In keeping with the critical area of gender transformation in the colleges, we would like to have had an equal number of men and women in the sessions. This was not possible given the small number of women holding permanent positions as lecturers so we tried to have at least one to two women from each college.

${ }^{4}$ Mela ("find a solution" in Amharic), is a role-playing serious game that aims to build the capacity of agricultural college instructors to prevent SGBV incidents and promote gender equality on campus. Throughout the six chapters of the game the player takes an instructor's role and is expected to address the gender-based issues that are raised on campus. Mela was developed in collaboration with a team of young Ethiopian game designers who supported the technical aspects of the process. See www.melagame.com or contact the first author.
} 
series of steps including working with a prompt or question (usually provided by the facilitator), brainstorming about issues in small groups, storyboarding, filming and screening, followed by reflecting. In our fieldwork, instructors were engaged in the process of cellphilm production in response to two prompts: "What are the potential roles of agricultural instructors in addressing SGBV issues on campus?" "What are the barriers that prevent instructors from addressing SGBV on campus?" In total, six cellphilms were created and were transcribed into text for analysis.

\section{Participatory Game Storyline Development Workshop}

The focus of our two-day workshop was to engage instructors in creating non-linear stories for a game as opposed to cellphilms, which just included linear narrations. Here, instructors from the four colleges developed four interactive storylines based on their lived experiences, and regarding the potential roles of instructors in preventing SGBV or promoting campus-based gender equality. These storylines offered alternative options for the audience to choose their path among the narrations. Instructors wrote and drew their ideas on flip charts and a representative of each group presented their overall story to everyone. With the consent of the instructors, we filmed the presentations and transcribed them later for analysis. We also photographed the flip charts for further review.

The cellphilm stories and the game storylines give a good sense of how the instructors were imagining and picturing change, and they also provided local and culturally relevant material that guided the game development team to develop the prototype of the serious game, Mela, and then the full game in later phases (see Sadati \& Mitchell, 2021, under review).

\section{Findings}

\section{Individual Interviews With Instructors}

The general thematic analysis steps outlined in Nowell et al. (2017) were adapted to analyse the interview data. We first familiarised ourselves with the data by reviewing the texts multiple times, generated initial codes using colour coding, created the themes, searched the data to ensure we had covered everything, and finally, we generated the report. Here, we categorise the findings from interviews in three groups: forms of SGBV on campus, causes of SGBV on campus, and consequences of SGBV on campus. ${ }^{5}$

\section{Forms of SGBV in the Agricultural Colleges}

Among the forms of SGBV shown in Table 1, are some that most of the instructors mentioned as being common problems (patriarchal practices; verbal and physical sexual harassment) whereas there are others that only a few instructors mentioned, such as coercive sex perpetrated by male staff members.

\footnotetext{
${ }^{5}$ Quotations in the tables are direct quotes from instructors.
} 
Table 1

Instructors Commenting on Forms of SGBV in the College

\begin{tabular}{|c|c|}
\hline General theme & Subcategories \\
\hline \multirow{2}{*}{ Patriarchal practices } & $\begin{array}{l}\text { Patriarchal behavior by male students such as: } \\
\text { - "Seizing the mobile phones of female students," } \\
\text { - "Keeping the educational resources (e.g., course handouts) to } \\
\text { - "Unemselves and not distributing them to female students," and } \\
\text { "Undermining the abilities of female students." }\end{array}$ \\
\hline & $\begin{array}{l}\text { Stereotypical patriarchal division of work between male and female students at } \\
\text { shared places such as: } \\
\text { - Cooking in group houses (which is a long process in this context) is done } \\
\text { by young women, thus giving them less time to study, while other } \\
\text { services (e.g., providing the cost) fall on men. }\end{array}$ \\
\hline \multirow{3}{*}{ Sexual harassment } & $\begin{array}{l}\text { Physical harassment of females such as: } \\
\text { - Touching, } \\
\text { - Biting, } \\
\text { - Taking women's scarves, } \\
\text { - Holding women against their will. }\end{array}$ \\
\hline & $\begin{array}{l}\text { Verbal harassment such as: } \\
\text { - Insulting women, } \\
\text { - Using impolite words to and about women, } \\
\text { - Making prejudgments like suggesting that women are weak mentally. }\end{array}$ \\
\hline & $\begin{array}{l}\text { Non-verbal signs or offensive body language such as: } \\
\text { - "Using inappropriate facial expressions," } \\
\text { - Making inappropriate gestures. }\end{array}$ \\
\hline
\end{tabular}

Spreading rumours about women engaging in sexual intercourse.

Sexual assault

Male staff members forcing sex on female students (and on female staff members).

Men raping women (just one interviewee pointed to this item without providing details).

Transactional sex

Female students agreeing to have sex with male students in exchange for having the latter do course assignments for them.

The implications of poor physical infrastructure
Considering the gender ratio, "the number of toilets for female students is inadequate."
Gender inequalities in organisational structure
There is no equal division of jobs between women and men, The employment rates are higher for men, and Women usually are not involved in management nor in decision-making. 
A significant point about the interviews was the instructors' tendency to highlight that they were not personally aware of any of the incidents mentioned, particularly those they called "hard or serious cases" such as any incident that involved sexual intercourse. In such cases, they usually started their responses with phrases like "I am not sure ..." or "I have not seen myself ..." "I have just heard that. .." or, "There are rumours around. .."

\section{Causes of SGBV in the Colleges}

The instructors referred to eight main causes of SGBV on campus, highlighting the role of a culture of toxic masculinity and the relative poverty of female students. As one participant stated: "The root cause is cultural beliefs." Table 2 shows the detail of synthesised data in response to the question, "What are the causes of SGBV on the campus?"

\section{Table 2}

\section{Instructors Commenting on the Causes of SGBV in the College}

\begin{tabular}{ll}
\hline General theme & Subcategories \\
\hline & Male students believe in their superiority, and this is shown in their behaviors. For \\
example, "males think they know everything," and, because females have less \\
intellectual capacity, they should obey them.
\end{tabular}

There is a risk of harassment/assault by male students against female students when the latter disagree with them.

Toxic masculinity culture
"Females (specifically from rural areas) are shy" and afraid to report the SGBV incidents.

The relatively better financial status of male students enables them to use their money for harassment purposes.

Internalised stereotypical gender-based attitudes are held by women and men.
Lack of knowledge and awareness
There is a lack of awareness in the males (students and instructors) about the consequences of SGBV against females.

There is a "lack of education about sex in families." Students (specifically girls) do not get adequate sex education.

Females lack knowledge about gender equity and about their rights.

Migration and mobility from rural to urban areas exposes females to violence because they do not have enough knowledge or the skills to combat it. 
The "lack of knowledge among some instructors regarding the consequences of SGBV for the country's development" leads to their lack of commitment to become actively involved in combating it.

Economic conditions

Poverty and economic problems lead female students to have transactional sex outside of the college.

$\begin{array}{ll}\begin{array}{l}\text { Lack of rules and } \\ \text { regulations }\end{array} & \begin{array}{l}\text { There are no comprehensive and separate regulations against SGBV in the } \\ \text { colleges. }\end{array}\end{array}$

Religious beliefs

"There is an article in the Bible and Quran that females should always respect and accept the power of their husband," according to one instructor.

Lower age and less

There is a "lack of maturity in students," many of whom are under 18 years of age, experience and this leads to an inability and/or unwillingness to address such violence.

Differences in individual attitudes and The managers, instructors, staff members, and students all have different attitudes understanding towards, and levels of understanding about, SGBV issues.

Poor physical infrastructure

There is a "shortage of facilities for female students," specifically toilets, and rest areas for pregnant women and nursing mothers. There are few facilities for the use of students' children, and this leads to discriminatory practices.

Here, we note that instructors identify cultural elements and poor infrastructure as both forms of SGBV and as causes of it. For example, the lack of proper toilets for females was identified as an example of gender-based discrimination, and, at the same time, as a reason for the lower attendance of pregnant female students in classes. Both affect their academic achievement.

\section{Consequences of SGBV in the Colleges}

Six themes were identified by instructors as consequences of SGBV on campus (see Table 3). Notable here, is the cause and consequence chain; each cause brings a related consequence, and, in turn, the consequence becomes the cause of another consequence. For example, shyness and lack of selfconfidence is the psychological consequence of different forms of SGBV, and, at the same time, it can prevent SGBV survivors from reporting the incidents-and this leads to their insecurity on campus. Furthermore, unwanted sexual intercourse can cause unwanted pregnancy, and, in turn, can lead to a female student being rejected by her family and community which, in turn, leads to her increased poverty. 


\section{Table 3}

Instructors Commenting on the Consequences of SGBV in the College

\begin{tabular}{|c|c|}
\hline General theme & Subcategories \\
\hline & Mental stress is suffered by females who fear males and what they might do. \\
\hline $\begin{array}{l}\text { Psychological issues } \\
\text { affecting female } \\
\text { students }\end{array}$ & $\begin{array}{l}\text { Females become shy and uncertain and participate less in activities, exhibit a lack } \\
\text { of self-confidence, and become isolated. }\end{array}$ \\
\hline
\end{tabular}

The overall environment demoralises women.

$\begin{aligned} & \text { Unwanted } \\ & \text { pregnancy and its }\end{aligned}$ This may lead to suicide or to the rejection of a woman by her family and the
consequences $\quad \begin{aligned} & \text { community. }\end{aligned}$
consequences academic Affected females might fail, withdraw, or stop learning.

Effects on females' achievements

$\begin{array}{ll}\text { Effects on females' } & \text { Women who suffer SGBV may come to believe that their lower economic status is } \\ \text { career and economic } & \begin{array}{l}\text { justified. } \\ \text { status }\end{array} \\ \text { Given the inequality in job opportunities for female students, they might become } \\ \text { sex workers (bar ladies) in off-campus bars. }\end{array}$

Health problems for Women might contract HIV and other STDs with related consequences such as females increased poverty.
Unbalanced development of the country
As an ultimate consequence, SGBV negatively affects the development of the country.

It is evident that forms, causes, and consequences are intertwined and real change would need the involvement of various sectors of, and stakeholders in, the community.

\section{Imagining Stories and Storylines}

As discussed in the methodology section, the instructors created narratives through two different activities: they produced short cellphilms, and they participated in a game-oriented storyline development workshop-both focusing on the role of instructors in gender transformation. These two participatory activities were used to encourage instructors to think about their real-life experiences on campus (e.g., their observations of SGBV issues and their conversations with students or colleagues about these) and to imagine what could reduce or prevent instances of SGBV in the colleges. The narratives of these two techniques were different mainly in terms of their structures: the narratives developed during cellphilm production aimed to be used in a short video, so they were linear with a fixed start and end point. However, the narratives developed during the participatory game storyline development workshop aimed to be used in a role-playing game, so they were non-linear including story branches and different paths for the player to select. 


\section{Storying Through Cellphilm Production}

Although there were various genres that the instructors could have chosen for their cellphilms (e.g., media messages, documentary style reporting, melodramas), all the groups chose to use what we have referred to elsewhere as melodramas (Sadati \& Mitchell, 2020), in which the group creates a type of role-play or a scenario.

The cellphilm, Providing Advice, seeks to raise awareness of instructors' potential role in intervening and solving some SGBV problems related to verbal harassment in the colleges. A male student uses verbal violence against a female student in a class and continues to do so even when the female asks him to stop. After class, the female student goes to the instructor's office and reports the issue. The instructor calls the male and female together to his office and explains why the male student's behaviour was wrong. Then the instructor asks the male student apologise to the female, which he does.

How to Report GBV focuses on how instructors can support female students in reporting incidents to gender clubs or other concerned bodies. A male student verbally harasses a female student who is on her way to a class. The female student runs away from the perpetrator, but she looks frustrated. An instructor sees her, asks about the problem and, after learning what happened, accompanies the female student to the gender club office to report the incident.

Supporting Survivors aims to inform instructors of their potential role as active bystanders and as advocates for female students. In the college computer lab, a male student is shown harassing a female student verbally and physically. The young woman, clearly in distress, leaves the lab. She explains to an instructor what happened and he helps her to meet the college's discipline committee. In the reconciliation meeting that is organised by the discipline committee, both perpetrator and female student are called in. During the discussion, the male student learns about his wrongful actions and understands that he was committing an abuse. He says that he will not repeat this. Then the female student returns to the lab and is able to work.

Rural Female Student and Communication targets the communication difficulties and shyness that some female students have, and which lead to their lack of participation in class. The cellphilm shows how instructors can address this issue specifically in relation to girls from traditional settings. In a class at an agricultural college, the instructor notices that a female student from a rural background does not participate in the class because she is shy. The instructor asks the student to meet him after the class when he takes the counselling role and advises her to stop feeling shy and to develop communication skills. In the next class, the female student participates more. Later, she demonstrates the courage to report an incident that happened in the class, which results in a male student being sent out. Finally, when the instructor announces the examination results, the grades of the female student have improved significantly. The instructor gives her a prize.

The Effect of Early Marriage on Female Students in Agriculture College highlights two ways in which instructors can support pregnant students (who might have difficulties on the campus and in their studies). The instructor introduces a pregnant student to the gender club and explains the facilities that they provide for females and specifically for pregnant students. The student goes to the gender club and learns about the waiting room where she can get some rest while at college. After the student gives birth, she comes to the college carrying her child to class. The cellphilm also shows how another instructor supports the female student by providing a special tutorial class to help her improve her work and compensate for the classes she missed during her maternity leave. However, despite all this support, the female student leaves the college because of the lack of proper childcare infrastructure. 
Lack of Instructor's Commitment to Respond to GBV Problem addresses the lack of commitment and sense of responsibility among some instructors regarding their college's SGBV issues. Two students (one male and one female) go to the instructor's office regarding an incident of gender-based violence that happened to a female student. The instructor is not in his office, and the students wait for him to come. After a long time, the instructor comes to the office and students share their concern, but the instructor notes the time and goes out of the office while telling the students to come back later because he does not have time for them.

\section{Storying Through Participatory Game Storyline Development}

In this phase, the instructors entered a new level of story development in creating storylines. A storyline in game development is defined as a sequence of events, and can be either linear or nonlinear/branching (Schell, 2020). In this stage, the instructors at each college formed a group, with each group selecting a topic about one of the potential roles of instructors in combating campus-based SGBV. The stories in this activity were developed with the intention of being used as game scenarios, so instructors made them in a choose-your-own-adventure style. In this type of storytelling, the creators of the story provide options throughout the storyline for the audience to choose between.

One of the storylines was about a college instructor who is supposed to contribute to creating awareness [among female students] on how to report and whom to report SGBV. In their story, one female student comes to the class but before she enters the classroom, a male student blocks her way. An instructor, who is on the way to their office, notices this situation. Here the instructor has two options: a) ignore the situation or b) try to intervene by providing advice. In the first case, the female student will be morally, psychologically, and academically affected. But in the case of the second option, the story continues with the instructor inviting both students to their office and providing advice to both. In this case, the instructor specifically gives directions to the female student about how to report such incidents to concerned bodies such as the gender office or the dean of students.

Another storyline was about the instructor providing advice to students in his office to address SGBV. In this story, the instructor is available in their office and a female student comes to share an insulting incident perpetrated against her by a male student. The instructor is given two options: a) the instructor welcomes the student and asks what happened and b) the instructor welcomes the female student into the office but after listening to an account of the insulting incident that happened to her, asks her to leave the office without helping her. Following the instructor's choice of the first option, the student informs the instructor about the problem and the fact that she cannot focus or actively participate in the class because of the insults. The instructor advises her not to be afraid and calls the insulter into the office. This student comes in and the instructor advises him to stop this disturbing behaviour not only towards this particular female student but also towards all female students. The male student regrets his action, accepts the advice, and promises to share this advice with other students and friends. In the second scenario, the student leaves while the problem is still unresolved. In this scenario, because there is no attention paid to the problem nor any suggested punishment, the male student not only continues insulting the same female but starts to insult other females as well. In this scenario, we see the impact on the examination results of female students, and we see that the number of females who attend the classes decreases. They struggle to achieve academically and drop out because of the verbal harassment that leads to their demoralisation.

A third story is about maximising self-confidence and minimising inferiority of female students. Before narrating the story, this group noted that although in most classes $59 \%$ of the students are female, they do not actively participate in the course activities and the class is dominated by males. The story starts in a classroom where the instructor asks a question and only one female student raises her hand to respond. The instructor wonders why only males respond. Here the story can continue with two 
alternative scenarios: a) the instructor can take action to address the issue somehow or b) the instructor can ignore the issue. In the first case, the instructor decides to encourage females to participate more in the class. Again, two options are given to the instructor: a) provide awards or recognition to females if they participate or b) provide more chances for them to participate. Providing awards or recognition leads to creating highly competitive students by increasing their self-confidence, and providing more opportunities by, for example, establishing rules like Ladies First, enables the females to participate and thereby increase their confidence. However, if the instructor chooses to ignore the situation, the female students might fail the course or withdraw.

A fourth group developed a storyline to show how an instructor can contribute to encouraging female students to break their silence and report SGBV incidents. In this story, about 40 students are in the practice or demonstration site and, in the meantime, a female student has been affected by an act of physical harassment. No one reports the incident to the instructor, but the instructor notices that something is wrong. To continue, there are two options: a) the instructor decides to follow the issue somehow and help the female student and b) the instructor ignores the case. In the first option, the instructor does not follow up with the female student directly, but informs another instructor to guide the affected female student to the college's gender club. The gender officer encourages and advises her, and she reports the case to them. The gender officer provides additional advice and takes her to the class. At the end of this scenario, the instructor invites the gender officer to the class to encourage and provide advice to all students. In the second option, the instructor ignores the case, and the female student stops attending the class. The instructor asks other students why this student does not come to the class anymore. The instructor also calls her family to ask why she stopped attending classes. The family attach a name, Kashalabeh [a local insulting label] to the female student and she becomes sad and goes in search of a job as a daily labourer. The instructor continues searching for her. Finally, the instructor finds her and takes her to the gender office so that they can help her.

\section{Analysis}

What can be seen in these cellphilms and storylines is, first, that although the overall number of stories is limited, the instructors were able to cover many of the items from all three categories: forms of SGBV, causes of SGBV, and consequences of SGBV. Second, all images of a better future and the instructors' role in creating a SGBV-free campus are based on changing the attitudes of individualsmale students (to cease engaging in their offensive behavior), female students (to stop being shy, and be brave enough to report these incidents), or instructors (to be more careful and responsible). None of the cellphilms or storylines offered ways of solving SGBV issues by addressing structural causes such as the patriarchal culture or the poverty and economic issues that were noted by most of the instructors in the interviews. Obviously, the instructors' capacity is limited to contributing to combating SGBV issues. Nevertheless, as discussed with one of the interviewees, trying to overcome some structural challenges, such as the poverty of some female students, by collecting money from volunteer instructors and staff is an example of a possible strategy. Third, all cellphilms and storylines that addressed issues of physical or verbal harassment (which are very common in the colleges, based on the interview data) suggested reconciliation as a solution. However, this is a traditional conflict resolution process that is taken for granted as the only (or main) method of solving harassment issues. In essence, although the instructors attempted to imagine change, they were often limited in the extent to which they could break out of conventional social norms.

What was significant about going beyond the cellphilm scenarios to develop the various choose-yourown-adventure options in the storyline workshop was the fact that in storylines, the narratives were non-linear and had different paths. This makes the storylines more interactive, and, in the final product (the serious game), gives the audience agency to choose their own adventure. Non-linear storyline 
development is one of the methods of creating interactive environments used in serious games to situate the player in decision-making spots similar to those that occur in real life circumstances.

Clearly, there were gaps in the range of scenarios imagined and this was also reflected in the interviews. For example, while most studies of campus-based SGBV have highlighted that instructors themselves can be perpetrators of SGBV (see Wende, 2016), this was not a scenario put forward in any of the cellphilms or storylines. However, the research team and game development team were able to integrate possible scenes and story paths in working with the storylines, which they, of course, took back to the instructors during the time of testing out the prototype of the game. To illustrate, in one scenario where a male instructor must meet with a female student in his office, one of the choices is to close the door for privacy or to keep the door open to make sure the interaction is completely safe for the student.

\section{Discussion}

SGBV is a social problem in Ethiopia that creates challenging and discriminatory situations for almost half of the population at different levels, including in post-secondary institutions. The studies that have explored such issues in the colleges and universities confirm the need for intervention programmes and yet the role of instructors, as potential agents of change in educational settings, has been understudied. Focusing on a narrative imagination or from the perspective of picturing change, we learned about instructors' knowledge of the current SGBV situations in the colleges and about their narratives of what they imagine an instructor's role could be in bringing change to the campus.

The cellphilms and storylines created a platform for instructors to externalise their imaginings of their roles in addressing SGBV, and, as such, they are tangible and transferable products that can be shared among all concerned bodies. Mitchell et al. (2017) have referred to the potential of cellphilms to be digital artifacts or "digital dialogue tools" that enable a diverse group of audiences (instructors and stakeholders) "to see the issues being raised [and] also to engage in dialogue with the issue under study for the purpose of facilitating social change" (p. 122). As people internalise the cultural and social meanings, they externalise their understandings in words, symbols, and artistic products (Zittoun \& Gillespie (2015); in that sense, "the only access we have to people's meaning making is through externalization" (p. 12).

Returning to the idea of Sools's (2020) prospective methodologies, we posit that such approaches are strategic and productive as interventions in and of themselves, feeding into pedagogies that are forward looking and, as Cherrington (2020) has noted, hopeful. Considering the devastating impact that SGBV can have on the lives of female students enrolled in colleges and universities, this position of hopefulness may seem somewhat naïve. However, without a view to making change, and without a process that allows the instructors to become actors, institutions will maintain the status quo. It was clear in the interviews that instructors are aware of many of the issues, but they have not been significantly engaged in imagining any what-next scenarios. But, through this cellphilm making and this creation of storylines, these instructors' thinking processes can be made available to various other stakeholders. This work could contribute to ensuring common understanding and lead to effective dialogue and real action to effect change.

Cultural resources provide us with materials such as experiences, images, narratives, and meanings that enable us to dream and explore promising futures (Zittoun \& Gillespie, 2015). Their socialisation into their culture is evident in the narratives of instructors-particularly when they perceive reconciliation to be a solution for verbal and physical harassment. Writing of the significance of peace building practices during the recent conflicts in Ethiopia, Tuso (2020) drew attention to peace and 
reconciliation in the broader African context. These reconciliation practices, based on the concepts of repentance by the perpetrator and the forgiveness of the victim/survivor, are used to resolve tensions. However, we know that such encounters can be highly distressing to the victim/survivor and alternative mechanisms and solutions, such as developing anti-harassment policies and regulations or launching anti-harassment training for male students, staff, and instructors should be considered. Establishing standard policies is key because the institutions are suffering from a lack of comprehensive rules and procedures that respond to sexual and gender-based harassment on campus. This is not to say that cultural practices should be ignored. Rather, it is an invitation to pay attention to Zittoun and Gillespie's (2015) point that "even individual experience is filtered through cultural meaning" (p. 56). We need to be conscious about and evaluate "the received residues of culture" that Bell $(1978$, p. 33) defined as the answers to our predicaments that we learn in society. The past affects our perceptions of the present, and our present images of the world shape our process of imagining the future. As Müller (2019) noted, in a social change process, past experiences can create the potential for us to move beyond the current situation toward new ways of being.

\section{Conclusion}

We acknowledge the role of Ethiopian agricultural college instructors as potential agents of change in their institutions. Yet, we consider the lack of a full and common understanding of current issues related to SBGV and some of those "received residues of culture" (Bell, 1978, p. 33) noted above, as potential challenges. Instructors occupy a strategic position in colleges in that they interact directly with students and also work directly with administrators. This position has a great deal of potential for developing intervention programmes that put these instructors in the centre. But instructors need to have an accurate image of the existing problems, and they also need to have the opportunity to externalise and share their vision of how to reimagine and reshape the current discriminatory realities.

We recognise, of course, that this utopic approach does not take full account of the actual in relation to the everyday lives of instructors and, especially, the time taken up by projects like the imaginings that were carried out in this small one working with 20 instructors and meeting four to five times over a few months. This was particularly difficult for the women instructors who participated in the project and who were often juggling a career as a scientist, and as a gender officer on top of their regular teaching duties and family responsibilities. For all instructors, this project of imagining and creating storylines was an add-on to their regular professional responsibilities. Moreover, the opportunities for professional learning are sparse in rural areas and even if instructors have a chance to participate in any, they face a variety of challenges such as balancing time, meeting budget, and infrastructure barriers. However, in having them participate in a process of creating an interactive self-educating tool (or serious game) for themselves in Ethiopian agricultural colleges to address campus-based SGBV, we see the findings as hopeful in supporting the notion of instructors being agents of change.

Finally, this article advocates for tools and methods that are future-oriented and that acknowledge the critical place of narrative imagining in transformation. It calls for further attention to the role of imagination and arts-based narrative techniques in addressing social issues. Also, it highlights the role of narrative imagination in designing intervention programmes that aim to prepare the members of a community to be agents of change in their local environment.

\section{Acknowledgement}

We are grateful to the Agricultural Transformation Through Stronger Vocational Education (ATTSVE) project (funded by Global Affairs Canada) for supporting the fieldwork, and, more than anything, we are indebted to the instructors in the four ATVET colleges, Maichew, Nedjo, Wolaita Sodo, and Woreta for their enthusiasm and commitment to the cause of creating safe spaces for teaching and learning. 
We also appreciate Fonds de Recherche du Québec-Société et Culture (FRQSC) and McGill Faculty of Education for their support throughout the conducting of this project. In addition, we are grateful for the grant from the International Development Research Centre (IDRC), Ottawa, Canada. The views expressed herein do not necessarily represent those of IDRC or its Board of Governors.

\section{References}

Abt, C. C. (1987). Serious games. University Press of America.

Adinew, Y. M., \& Hagos, M. A. (2017). Sexual violence against female university students in Ethiopia. BMC International Health and Human Rights, 17. https://doi.org/10.1186/s12914-017-0127-1

Andrews, M. (2014). Narrative imagination and everyday life. Oxford University Press. https://oxford.universitypressscholarship.com/view/10.1093/acprof:oso/9780199812394.001.00 01/acprof-9780199812394

Arnold, D., Gelaye, B., Goshu, M., Berhane, Y., \& Williams, M. A. (2008). Prevalence and risk factors of gender-based violence among female college students in Awassa, Ethiopia. Violence and Victims, 23(6), 787-800. https://doi.org/10.1891/0886-6708.23.6.787

Bell, D. (1978). The return of the sacred: The argument about the future of religion. Bulletin of the American Academy of Arts and Sciences, 31(6), 29-55. https://doi.org/10.2307/3823029

Beyene, A. S., Chojenta, C., Roba, H. S., Melka, A. S., \& Loxton, D. (2019). Gender-based violence among female youths in educational institutions of sub-Saharan Africa: A systematic review and metaanalysis. Systematic Reviews, 8(1), 59. https://doi.org/10.1186/s13643-019-0969-9

Brockmeier, J. (2009). Reaching for meaning: Human agency and the narrative imagination. Theory \& Psychology, 19(2), 213-233. https://doi.org/10.1177/0959354309103540

Cherrington, A. M. (2020). Visions of hope in education: Fostering student teachers' identities of becoming agents of change through a photo competition and exhibition. In H. Mreiwed, M. R. Carter, \& C. Mitchell (Eds.), Art as an agent for social change (pp. 75-84). Brill | Sense. https://doi.org/10.1163/9789004442870

D'Amico, M., Denov, M., Khan, F., Linds, W., \& Akesson, B. (2016). Research as intervention? Exploring the health and well-being of children and youth facing global adversity through participatory visual methods. Global Public Health, 11(5/6), 528-45. https://doi.org/10.1080/17441692.2016.1165719

de Lange, N., Mitchell, C., \& Stuart, J. (Eds.). (2007). Putting people in the picture: Visual methodologies for social change. Sense Publishers.Eisner, E. W. (2002). The arts and the creation of mind. Yale University Press. http://site.ebrary.com/id/10170753

Gelaye, B., Arnold, D., Williams, M. A., Goshu, M., \& Berhane, Y. (2009). Depressive symptoms among female college students experiencing gender-based violence in Awassa, Ethiopia. Journal of Interpersonal Violence, 24(3), 464-481. https://doi.org/10.1177/0886260508317173

Graef, J., da Silva, R., \& Lemay-Hebert, N. (2020). Narrative, political violence, and social change. Studies in Conflict \& Terrorism, 43(6), 431-443. https://doi.org/10.1080/1057610X.2018.1452701

Greene, M. (1999). Art and imagination: Overcoming a desperate stasis. In A. C. Ornstein \& L. S. BeharHorenstein (Eds.), Contemporary issues in curriculum (2nd ed., pp. 45-53). Allyn and Bacon. WorldCat.org. http://hdl.library.upenn.edu/1017.12/366263

Hawlina, H., Pedersen, O. C., \& Zittoun, T. (2020). Imagination and social movements. Current Opinion in Psychology, 35, 31-35. https://doi.org/10.1016/j.copsyc.2020.02.009 
Jenkins, H., Peters-Lazaro, G., \& Shresthova, S. (2020). Popular culture and the civic imagination: Case studies of creative social change. New York University Press. http://ebookcentral.proquest.com/lib/mcgill/detail.action?doclD=5994221

Kassa, S., Molla, A., \& Cherie, N. (2019). Sexual coercion and determinant factors among female students in Wollo University, Ethiopia. Kenkyu Journal of Epidemiology \& Community Medicine, 5, 1-13. https://doi.org/10.31872/2018/KJECM-100117

Kefale, B., Yalew, M., Damtie, Y., Arefaynie, M., \& Adane, B. (2021). Predictors of sexual violence among female students in higher education institutions in Ethiopia: A systematic review and metaanalysis. PLOS ONE, 16(2), e0247386. https://doi.org/10.1371/journal.pone.0247386

Leach, F. E., \& Mitchell, C. (2006). Combating gender violence in and around schools. Trentham Books.

Low, B., Brushwood Rose, C., Salvio, P. M., \& Palacios, L. (2012). (Re)framing the scholarship on participatory video. In E. J. Milne, C. Mitchell, \& N. de Lange (Eds.), Handbook of participatory video (pp. 50-63). AltaMira Press.

Mamaru, A., Getachew, K., \& Mohammed, Y. (2015). Prevalence of physical, verbal and nonverbal sexual harassments and their association with psychological distress among Jimma University female students: A cross-sectional study. Ethiopian Journal of Health Sciences, 25(1), 29-38.

Mertens, D. M. (2008). Transformative research and evaluation. Guilford Press.

Mitchell, C. (2009). Geographies of danger: School toilets in sub-Saharan Africa. In O. Gershenson \& B. Penner (Eds.), Ladies and gents: Public toilets and gender (pp. 62-74). Temple University Press. WorldCat.org. http://www.h-net.org/reviews/showrev.php?id=30896

Mitchell, C., de Lange, N., \& Moletsane, R. (2016). Me and my cellphone: Constructing change from the inside through cellphilms and participatory video in a rural community. Area, 48(4), 435-441. https://doi.org/10.1111/area.12142

Mitchell, C., de Lange, N., \& Moletsane, R. (2017). Participatory visual methodologies: Social change, community and policy. SAGE.

Mitchell, C., \& Starr, L. J. (2018). Report on survey/assessment on gender based violence in four ATVET colleges: Woreta, Nedjo, Wolaita Sodo \& Maichew. Participatory Cultures Lab, Faculty of Education, McGill University. https://glcopmcgill.ca/wp-content/uploads/2019/11/Final-GBVsurvey-analysis.012718-copy.pdf

Mreiwed, H., Carter, M. R., \& Mitchell, C. (Eds.). (2020). Art as an agent for social change. Brill | Sense. https://doi.org/10.1163/9789004442870

Müller, M. (2019). Inside a box: Using objects to collaboratively narrate educator experiences of transformation in higher education. Educational Research for Social Change, 8(1), 54-69. https://doi.org/10.17159/2221-4070/2018/v8i1a4

Nowell, L. S., Norris, J. M., White, D. E., \& Moules, N. J. (2017). Thematic analysis: Striving to meet the trustworthiness criteria. International Journal of Qualitative Methods, 16(1). https://doi.org/10.1177/1609406917733847

Razack, S. (2006). Story-telling for social change. Gender and Education, 5(1), 55-70. https://doi.org/10.1080/0954025930050104

Sadati, S. M. H. (2019). Serious games as self-educating tools: A case study to address SGBV. Participatory Cultures Lab, Faculty of Education, McGill University. http://melagame.com/wpcontent/uploads/2020/02/Serious-Games-as-Self-educating-Tools-Briefing-Paper.-Sadati2019.Final.pdf 
Sadati, S. M. H., \& Mitchell, C. (2020). Playing into change: On the use of cellphilming to create storylines for a serious game to address sexual and gender based violence in rural agricultural colleges in Ethiopia. In K. Gillander Gådin (Ed.), Våld, trakasserier och diskriminering: Ett globalt problem i en lokal kontext [Gendered violence, harassment and discrimination: A global problem in a local context] (pp. 124-134). Forum for Gender Studies. https://www.divaportal.org/smash/record.jsf?pid=diva2\%3A1443557\&dswid=-6914

Sadati, S. M. H., \& Mitchell, C. (2021). Serious game design as research-creation to address sexual and gender-based violence. International Journal of Qualitative Methods, 20, 1-16. https://doi.org/10.1177/16094069211046130

Sadati, S. M. H., \& Mitchell, C. (2021, under review). Participatory arts-based game design: Mela, a serious game to address SGBV in Ethiopia [Manuscript submitted for publication]. Faculty of Education, McGill University.

Schell, J. (2020). The art of game design: A book of lenses (3rd ed.). CRC Press. https://www.routledge.com/The-Art-of-Game-Design-A-Book-of-Lenses-ThirdEdition/Schell/p/book/9781138632059

Shimekaw, B., Megabiaw, B., \& Alamrew, Z. (2013). Prevalence and associated factors of sexual violence among private college female students in Bahir Dar city, North Western Ethiopia. Health, 5(6), 720-726. https://doi.org/10.4236/health.2013.56143

Smith, D. W. (2018). Phenomenology. In E. N. Zalta (Ed.), The Stanford encyclopedia of philosophy. https://plato.stanford.edu/archives/sum2018/entries/phenomenology/

Sools, A. (2020). Back from the future: A narrative approach to study the imagination of personal futures. International Journal of Social Research Methodology, 23(4), 451-465. https://doi.org/10.1080/13645579.2020.1719617

Starr, L., \& Mitchell, C. (2018). How can Canada's feminist international assistance policy support a feminist agenda in Africa? Challenges in addressing sexual violence in four agricultural colleges in Ethiopia. Agenda, 32(1), 107-118. https://doi.org/10.1080/10130950.2018.1427692

Takele, A., \& Setegn, T. (2014). Sexual coercion and associated factors among female students of Madawalabu University, Southeast Ethiopia. Advances in Public Health, 2014. https://doi.org/10.1155/2014/417517

Tomaselli, K., Dockney, J., \& Hart, T. (2010). Cellphilms, mobile platforms and prodsumers: Hyperindividuality and film. In N. Hyde-Clarke (Ed.), The Citizen in communication: Revisiting traditional, new and community media practices in South Africa (pp. 75-96). Juta.

Tora, A. (2013). Assessment of sexual violence against female students in Wolaita Sodo University, Southern Ethiopia. Journal of Interpersonal Violence, 28(11), 2351-2367. https://doi.org/10.1177/0886260512475316

Tuso, H. (2020). Peace and reconciliation, the essential pre-existing conditions: Implications for the current situation in Ethiopia (Paper prepared for the Forum for Promoting Reconciliation, Peace, and Democracy Building in Oromia and Ethiopia). https://ollaa.org/wpcontent/uploads/2020/01/Peace-and-Reconciliation-paper waltana.pdf

Wende, M. (2016). Sexual harassment against female students in higher institution: The case of Ambo University (Paper presented at St. Mary's University's 8th multi-disciplinary seminar. http://repository.smuc.edu.et/bitstream/123456789/3010/1/Mulugeta.pdf

World Bank. (2019). Gender-based violence (violence against women and girls). World Bank. https://www.worldbank.org/en/topic/socialsustainability/brief/violence-against-women-andgirls 
Zittoun, T., \& Gillespie, A. (2015). Imagination in human and cultural development. Taylor \& Francis. http://ebookcentral.proquest.com/lib/mcgill/detail.action?doclD=3569921 